\title{
Late Presentation of an Ingested Partial Denture
}

\author{
Mohammed Saleh, Dulani Mendis
}

\begin{abstract}
Introduction: Impacted foreign bodies in the esophagus and trachea are a common occurrence in the adult population, with patients often presenting with a variety of vague symptoms [1, 2]. Case Report: We report a case of a patient who accidentally swallowed his partial dentures and presented to our Ear, Nose and Throat department nine weeks later despite numerous presentations to primary and secondary care. The four-toothed partial denture plate was successfully removed under a general anesthetic and after a period of nasogastric feeding the patient was discharged home uneventfully on a normal diet, on the fourth post-operative day following a normal contrast swallow study. Conclusion: This case reiterates the importance in obtaining a thorough history and examination in establishing the correct diagnosis facilitating prompt specialist referral and ultimately definitive management.
\end{abstract}

Keywords: Dentures, Esophageal foreign body, Esophagoscopy

$* * * * * * * * *$

Dr Mohammed Saleh ${ }^{1}$, Miss Dulani Mendis ${ }^{1}$

Affiliations: ${ }^{1}$ Dept ENT Surgery, New Cross Hospital, Wednesfield Road, Wolverhampton, WV10 0QP, United Kingdom.

Corresponding Author: Miss D. Mendis; Phone: 01902307999; Fax: 01902695634; Email: dulanimendis@yahoo.com

Received: 29 November 2011

Accepted: 04 March 2011

Published: 01 July 2011
Saleh M, Mendis D. Late presentation of an ingested partial denture. International Journal of Case Reports and Images 2011;2(7):13-16.

$$
* * * * * * * * *
$$

doi:10.5348/ijcri-2011-07-44-CR-4

\section{INTRODUCTION}

One in five people aged 18-74 have full or partial dentures [1]. Accordingly, impacted foreign bodies in the esophagus and trachea are a common occurrence in the adult population. Abdullah et al. in 1998, reported that dental prosthesis accounted for $11.5 \%$ of impacted tracheal or esophageal foreign bodies [2]. Diagnosis of denture impaction can be challenging as patients often present with vague symptoms and maybe are unaware of swallowing their dentures. Radiological diagnosis may be impeded by the presence of radiolucent acrylic resins (methylmethacrylate i.e. PMMA) in the dentures. Other denture materials such as porcelain and plastic artificial teeth are also difficult to visualize on plain radiographs [3]. Delayed presentation may be associated with significant complications secondary to trauma to and perforation of the upper aerodigestive tract.

This clinical case demonstrates the importance of a thorough history and examination in patients presenting with dysphagia associated with foreign body impaction, initiating early specialist referral.

\section{CASE REPORT}

A previously fit and well, 53-year-old male smoker referred by the emergency department presented to our Ear, Nose and Throat (ENT) department with a 
nine week history of dysphagia to solids, regurgitation of undigested food and weight loss of approximately 19 kilograms. The patient had presented nine weeks earlier to the emergency department with a foreign body sensation and a history of a missing denture plate. Retrospectively the patient was unsure if this was misplaced or taken off prior to sleeping. Following normal radiological investigations the patient was discharged to return six weeks later with the same problem. The case was ultimately referred to the ENT emergency clinic after a further presentation to primary and secondary care. Other notable aspects of the history consisted of a 35 pack-year smoking history and an alcoholic consumption of 35 units a week.

Specialist ENT examination including flexible nasoendoscopy was non-specific, revealing hypopharyngeal salivary pooling with no obvious foreign body. The patient was admitted for further management due to the significant and worrying symptoms. The history and timing of events prompted the clinical suspicion of an impacted foreign body. The differential diagnoses also included a possible malignant process. The patient was commenced on intravenous fluids and antibiotics and routine blood tests were arranged, which were normal. A chest X-ray was normal however, a lateral soft tissue neck radiograph was significantly abnormal (Figure 1). Furthermore, subsequent CT imaging (neck/thorax) confirmed the presence of a hyper dense foreign body resembling a ridged plastic membrane in the hypopharynx extending from the base of the pyriform fossa to the post cricoid esophagus (Figure 2).

The patient underwent a laryngopharyngoscopy and rigid upper esophagoscopy, which confirmed the presence of an impacted 4-toothed denture plate (acrylic resin-type) which was subsequently removed from the post-cricoid region using pharyngeal forceps (Figure 3). The impacted denture, present for nine weeks had eroded the upper surface of cricoid cartilage and caused significant hypopharyngeal, post-cricoid and upper esophageal edema. The significant risk of mucosal perforation necessitated the passage of a fine bore nasogastric (NG) tube for feeding.

Post-operatively, the patient was monitored closely for any signs of surgical emphysema or mediastinitis. NG feeds were commenced after tube position was confirmed and the patient was kept nil by mouth. On the third post-operative day the patient underwent a normal water soluble contrast swallow study and was finally discharged home the following day with oral antibiotics. Subsequent review at a two week follow-up appointment was uneventful.

\section{DISCUSSION}

There have been many case reports documenting denture impaction in the esophagus, with some cases presenting up to six months later [4]. In adults ingestion usually occurs after trauma, intoxication, loss of consciousness or sleep [5]. Elderly, pediatric and psychiatric patients or those with learning disabilities, particularly those who have been sedated are at greater risk of denture ingestion [6]. Diagnosis can be challenging as patients can present with a variety of vague symptoms such as neck pain, dysphonia, dysphagia, excessive salivation, sore throat, choking sensation, retrosternal pain, fever, hemoptysis, regurgitation of undigested food and odynophagia [3]. Furthermore, radiolucency of dentures makes radiological diagnosis difficult. In this case the initial $\mathrm{X}$-ray nine weeks prior to referral did not show a

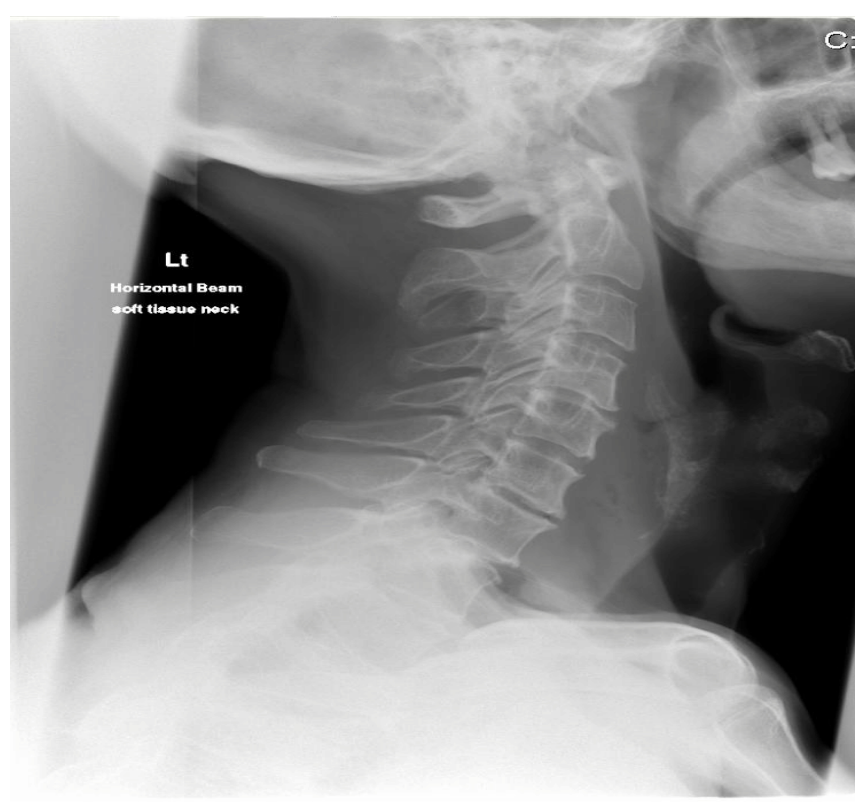

Figure 1: Lateral soft tissue neck radiograph demonstrating air within the hypopharynx and soft tissue edema anterior to $\mathrm{C}_{5}-\mathrm{C} 7$.

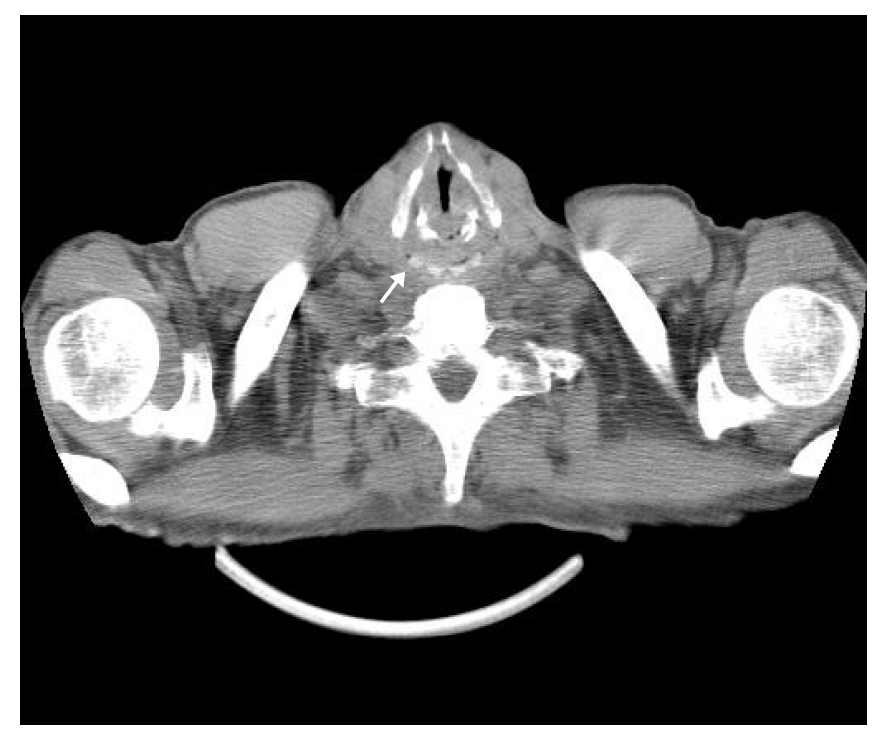

Figure 2: CT scan neck/thorax demonstrating the visible four-toothed denture plate (arrowed). 

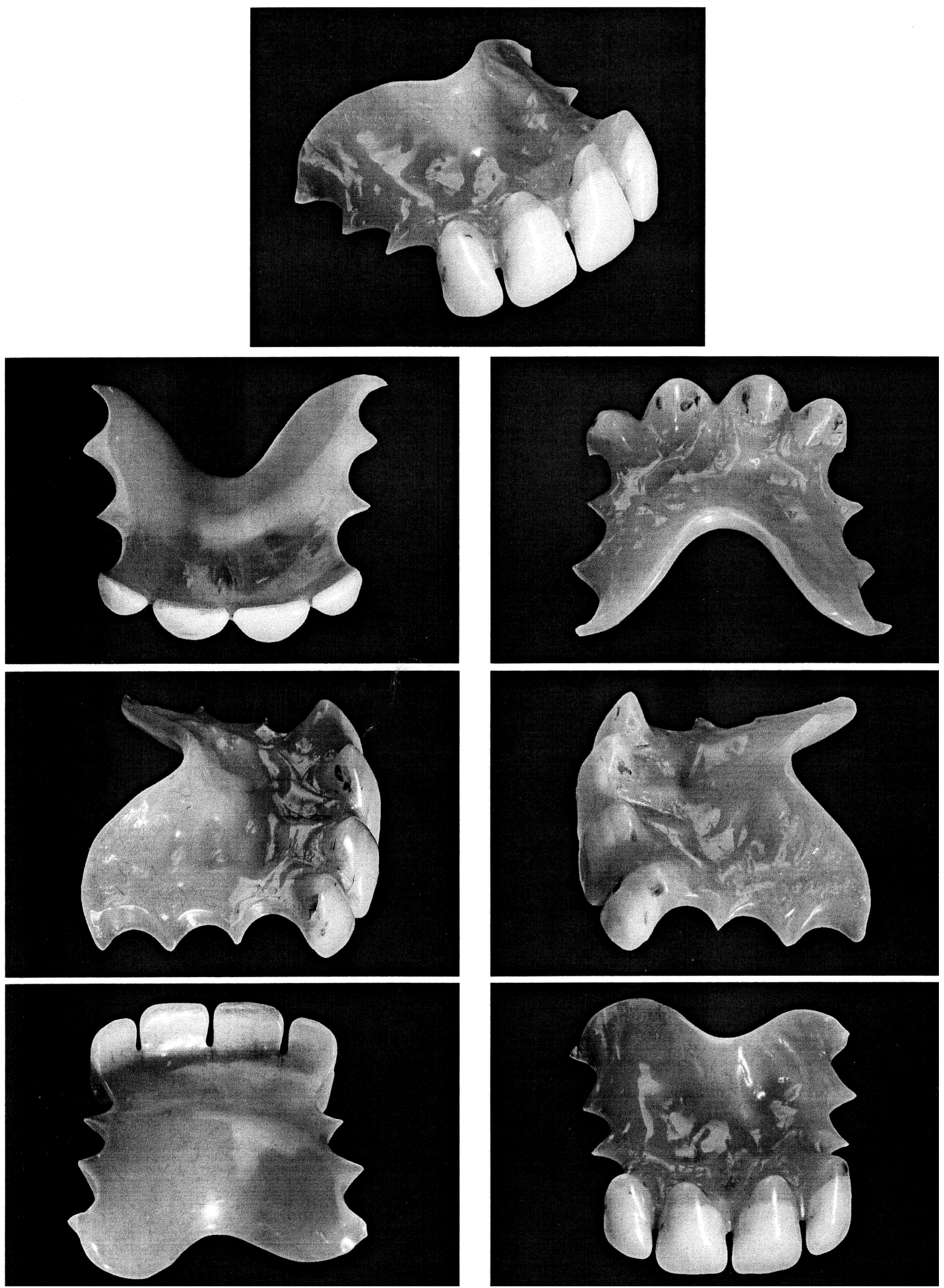

Figure 3: Impacted 4-toothed denture plate. 
positive foreign body. This case highlights the need for a high degree of suspicion as well as a thorough ENT history and examination to detect foreign bodies. Thus, a normal soft tissue X-ray does not exclude the presence of a foreign body. Abdullah et al. in 1998, reported that only $22 \%$ of dental prostheses impacted in the esophagus showed evidence of a foreign body on the lateral soft tissue neck radiograph [2].

In addition, this case supports the need for the inclusion of a radio-opaque marker in acrylic based dentures, as this may reduce the incidence of missed or delayed diagnoses. Although there have been attempts to create a radio-opaque resin base, their physical and aesthetic qualities do not match that of PMMA [7].

It is important to recognize that ill-fitting and damaged dentures constitute a risk factor for accidental ingestion as does sleeping with dentures left in-situ [5]. Therefore, it is important to discourage patients from wearing them while asleep and from using either ill-fitting or damaged dentures.

The patient in this case did not suffer any complications but a delay in diagnosis and treatment, which can be associated with complication rates rising from $3.2 \%$ after 24 hours to $23.5 \%$ after 48 hours [8, 9]. Serious documented complications have included obstruction and perforation of the esophagus, mediastinitis, pneumothorax, pneumopericardium, tracheoesophageal, aortoesophageal and even esophago-broncho-aortic fistulas, aortic erosion, enterocolonic fistulas and colonic perforation [10].

\section{CONCLUSION}

We reiterate the important of a thorough ENT history and examination, which in itself maybe vague with few clinical signs and negative radiological investigations. However, it remains of vital importance to have a high index of suspicion to avoid any delay in appropriate specialist referral to ENT for ultimate endoscopic management. This case supports the need for the inclusion of radio-opaque markers in denture production to expedite diagnosis and treatment.

$* * * * * * * * *$

\section{Author Contributions}

Mohammed Saleh - Substantial contributions to conception and design, Acquisition of data, Analysis and interpretation of data, Drafting the article, Revising it critically for important intellectual content, Final approval of the version to be published

Dulani Mendis - Substantial contributions to conception and design, Acquisition of data, Analysis and interpretation of data, Drafting the article, Revising it critically for important intellectual content, Final approval of the version to be published

\section{Guarantor}

The corresponding author is the guarantor of submission.

\section{Conflict of Interest}

Authors declare no conflict of interest.

\section{Copyright}

(C) Mohammed Saleh et al. 2011; This article is distributed under the terms of Creative Commons attribution 3.0 License which permits unrestricted use, distribution and reproduction in any means provided the original authors and original publisher are properly credited. (Please see www.ijcasereportsandimages.com /copyright-policy.php for more information.)

\section{REFERENCES}

1. Redford M, Drury TF, Kingman A and Brown LJ. Denture use and the technical quality of dental prostheses among persons 18-74 years of age: United States, 1988-1991. J Dent Res. 1996;75:71425.

2. Abdullah BJ, Teong LK, Mahadevan J, et al. Dental prosthesis ingested and impacted in the esophagus and orolaryngopharynx. J Otolaryngol. 1998;27:190-4.

3. Haidary A, Leider JS, Silbergleit. Unsuspected Swallowing of a Partial Denture. Am J Neuroradiol. 2007;28:1734.

4. Rathore PK, Raj A, Sayal A, Meher R, Gupta B, Girhotra M. Prolonged foreign body impaction in the esophagus. Singapore Med J. 2009;50(2):e5354 .

5. Firth AL, Moor J, Goodyear PWA, Strachan: Dentures may be radiolucent. Emerg Med J. 2003;20:562-3.

6. De Ruiter MH, Van Damme PA, Drenth JP. Serious complications following removal after ingestion of a partial denture. Ned Tijdschr Tandheelkd. 2008;115(5):267-70.

7. Tsao DH, Guilford HJ, Kazanoglu A, et al. Clinical evaluation of a radiopaque denture base resin. $\mathrm{J}$ Prosthet Dent. 1984;51:456-8.

8. Yeoh NTL. Impacted dentures in the esophagus. Med J Malaysia. 1982;37:344-8.

9. Lim CT, Quah RF, Loh LE. A prospective study of ingested foreign bodies in Singapore. Arch Otolaryngol Head Neck Surg. 1994;120:96-102.

10. Kulendra KN, Skilbeck CJ, Blythe J, Choa DI. Delayed presentation of a swallowed partial denture. BMJ case reports 2010; doi:10.1136/bcr.10.2009.2401 